\section{A Lesson Not Yet Learned}

GW Becker, TJ Laundy
Sqn Ldr GW Becker MA MB BChir MRCS RAF

Registrar in

MDHU Derriford.

Email :

gwb@doctors.org.uk

Gp Capt TJ Laundy

BSc MB BS FRCP

DipAvMed RAF

Consultant Physician MDHU Peterborough.

\begin{abstract}
Objectives:

Accounts of numerous military campaigns throughout history have shown that casualties from medical illness usually greatly outnumber combat injuries. We aimed to see whether this remained the case in a modern campaign where predominantly surgical facilities were deployed.
\end{abstract}

\section{Methods}

We examined 1511 hospital records of inpatients in the Oman theatre during the last three months of Exercise Saif Sareea II and the initial period of Operation Veritas.

\section{Results}

Of the 1399 records included, 1033 (74\%) required care from a physician, whereas $366(26 \%)$ were treated by surgeons. However, of patients returning to duty in theatre (total 985), $884(90 \%)$ had been treated by physicians and 101 had been treated by surgeons. Notably, only 23 $(2 \%)$ of these had undergone a surgical procedure.

\section{Conclusions}

Experience in Oman suggests that the lessons of history in respect of casualties in times of conflict are both unlearned and being repeated. The role of the medical specialities in military secondary care should be recognised and deployed facilities should not be defined by surgical capability alone.

\section{Introduction}

Those who cannot remember the past are condemned to repeat it (1).

Throughout history, war and disease have been constant companions. Deaths from disease have often exceeded battlefield deaths, with typhus, typhoid, plague, cholera and dysentery deciding more campaigns than the great generals of history.

In July 1809, a British Expeditionary force of 40,000 departed for Walcheren in Belgium to campaign against Napoleon. By August, military objectives were submerged in an epidemic of disease affecting $40 \%$ of the army. 3,600 soldiers and 60 officers died. There were 16,000 medical casualties compared with only 100 killed in sporadic fighting; the predominant symptom was fever - the likely causes malaria, typhoid, typhus and dysentery (2).

In the 1853-56 Crimean War, although there were significant battle casualties, deaths from disease vastly exceeded combat deaths. Of the British army, 18,283 were treated for wounds, but 144,390 were treated for medical problems. 4,947 were killed in action or died of their wounds, yet 17,225 died from disease (3).

In 1942 in Burma, the allies under Lieutenant General Sir William Slim suffered a long and disastrous retreat before the advancing Japanese - the health of the retreating 14th Army was described as 'dismal.' For each wounded man evacuated, 120 were evacuated with illness (4).

The malaria rate was $84 \%$ of total troop strength per annum, even higher in the front line.

"A simple calculation showed me that at this rate my army would have melted away. Indeed, it was doing so before my eyes ... the battle against disease is fought not only by doctors but also by regimental officers ... If mepacrine was not taken, I sacked the commander. I only had to sack three; by then the rest had got my meaning ... Slowly, but with increasing rapidity, as all of us, commanders, doctors, regimental officers, staff officers and NCOs united in the drive against sickness, results began to appear. On the chart that hung on my wall the curves of admissions to hospitals and malaria sank lower and lower."

As a result of Field Marshal Slim's policy of using military discipline to enforce medical policies, by 1945 the sickness rate for the whole 14th Army was reduced to one, per thousand, per day.

In the Vietnam War, $70 \%$ of all hospital admissions were due to infectious diseases: malaria, dengue fever, scrub typhus and Japanese encephalitis.

In the 1979-1989 Soviet invasion of Afghanistan, 620,000 Soviet troops were deployed over 10 years. 14,453 died from all causes. 469,685 were hospitalised, with only 53,753 wounded or injured. 415,932 (67\%) of the total Soviet military population who served in Afghanistan required hospitalisation for medical illness (5).

In Gulf War I, 90\% of hospital admissions were for Disease and Non-Battle Injury (DNBI) causes and in Somalia, 95\% of the 
requirement for secondary care was for infectious disease (6).

During the joint British / Omani Exercise Saif Sareea II in 2001, secondary care facilities comprising a mixture of role $2+$ and role 3 units (Field Hospitals) were deployed. They were configured predominantly toward the provision of surgical (general and orthopaedic) care. At the height of the exercise, an additional consultant physician was deployed into theatre at short notice, in light of "an unanticipated number of emergency medical admissions".

\section{Method}

We examined the admission records of inpatients in Units of 22 Field Hospital and the Royal Air Force Hospital Thumrait for the last three months of Exercise Saif Sareea II (21 Aug 2001 - 5 Nov 2001) and the initial period of Operation Veritas in Oman and Afghanistan (5 Nov 2001 - 29 Jan 2002). 1511 records were categorised by diagnosis, speciality, treatment and outcome. The allocation to a speciality followed conventional diagnostic criteria, but reflected the limited range of specialists who provide care under field conditions. Treatment was classified as operative or non-operative and disposal was classified into return to duty in theatre or evacuation (aeromedical or transfer to Host Nation facilities).

\section{Results}

Of the 1511 admissions, 37 were categorised as Obstetrics \& Gynaecology, Dental or No Diagnosis/Speciality and were excluded. 75 further episodes were identified as in-theatre transfers between units (duplicates) and also excluded.

Of the 1399 records remaining, 1033 (74\%) were medical cases and 366 (26\%) were surgical (General Surgery, Orthopaedics, Ear Nose and Throat, Urology, Plastics, Ophthalmology).

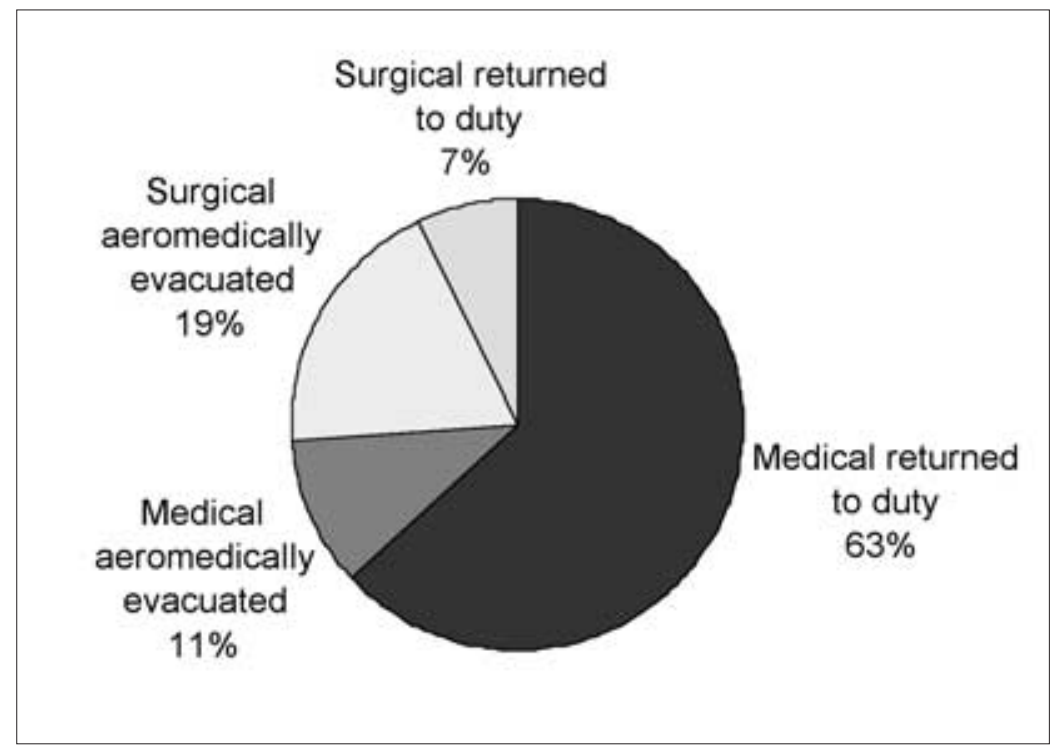

Fig 1. Breakdown of caseload.
Of the 1033 medical cases, 884 (86\%) were returned to duty in theatre after treatment, in contrast to only $101(28 \%)$ of the surgical cases. The remaining 149 medical cases (14\%) and 265 surgical cases $(72 \%)$ required evacuation to the $\mathrm{UK}$ or Host Nation facilities (Figure 1).

From a treatment viewpoint, $884(86 \%)$ of the patients treated medically returned to duty in theatre. 32 patients had a surgical procedure and were subsequently evacuated from theatre. Only $23(6 \%$ of patients treated by surgeons) returned to duty in theatre following a surgical procedure. Of those 23 surgical procedures, 12 were emergency procedures, 11 were elective, and none were major cases (Table 1).

Table 1. Surgical procedures performed (Patients returned to duty).

\begin{tabular}{|l|l|}
\hline & ELECTIVE \\
\hline 10 & Minor Skin Lesion Excisions \\
\hline 1 & $\begin{array}{l}\text { Excision and suture Pilonidal } \\
\text { Sinus }\end{array}$ \\
\hline 3 & $\begin{array}{l}\text { EMERGENCY } \\
\text { laceration }\end{array}$ \\
\hline 1 & $\begin{array}{l}\text { Debridement shrapnel wound } \\
\text { abdomen }\end{array}$ \\
\hline 1 & $\begin{array}{l}\text { Relocation of dislocated PIPJ } \\
\text { Removal of Foreign Body from } \\
\text { thumb }\end{array}$ \\
\hline 1 & \begin{tabular}{l} 
Incision and drainage abscess \\
\hline
\end{tabular} \\
\hline
\end{tabular}

\section{Discussion}

In both peacetime and conflict, more military patients are dealt with in primary care than in hospital. Nevertheless, within the period examined, almost $9 \%$ of Exercise Saif Sareea II and Operation Veritas personnel became ill enough to be hospitalised at some time, a finding in keeping with historical experience.

In this analysis of 1399 hospital admissions, 985 personnel were returned to duty in theatre. $884(90 \%)$ required care from a physician, whereas only $101(10 \%)$ required treatment by a surgeon. Only 23 actually had surgery and returned to duty; the majority of this surgery was elective. Whilst the majority of the medical cases were for gastroenteritic or heat-related illness, many of these were seriously ill and required specialist physician care.

Most medical patients return to productive duty and the majority of patients ill enough to require hospital care require the services of a physician. In contrast, most surgical patients require evacuation out of theatre surgery seldom returns personnel to duty within the time span of a military operation. Force maintenance and preservation is 
therefore served better by medical specialities.

This does not diminish the vital importance of surgical teams when the trauma or surgical patient presents. Moral, ethical, morale and political considerations mandate the provision of surgical facilities but medical, physician based, services provide more support to the operational effort.

\section{Conclusion}

Recent experience in Oman suggests that the lessons of history in respect of casualties in times of conflict are both unlearned and being repeated. The medical manpower and equipment modules provided matched neither the numbers requiring treatment nor the outcome support to operational activity. The role of the medical specialities in military secondary care should be recognised and facilities should not be defined by surgical capability alone. In addition, planning, recruitment and call-up initiatives need to take these observations into account. The authors hope that a retrospective analysis of hospital cases from Gulf War II (Operation Telic) will show that this lesson has finally been learnt.

\section{References}

1. Santayana G. Life of Reason, Reason in Common Sense (Great Books in Philosophy). New York: Prometheus Books; 1998.

2. Howard M. Walcheren 1809: a medical catastrophe. BMJ 1999; 319:1642-1645.

3. Zinsser H. Rats, Lice and History. Boston: Little, Brown \& Co; 1934.

4. Bellamy RF, Llewellyn CH. Preventable Casualties: Rommel's Flaw, Slim's Edge. Army 1990; May:52-56.

5. Grau L, Jorgensen W. Medical Support in a Counter-Guerrilla War: Epidemiologic Lessons Learned in the Soviet-Afghan War. U.S. Army Med Dep J 1995; May/June: 41-49.

6. Website of the Office of the Assistant Secretary of Defense (Health Affairs) USA.

http:/www.ha.osd.mil/forcehealth/library/docs/ FHP_capstone3.doc. 